\title{
Research on the Penetration of Discourse Analysis in Witting Teaching of College English
}

\author{
Juanjuan Hou \\ School of Foreign Languages, Yan'an University, Yan’an, 716000, China
}

Keywords: Discourse analysis, Witting teaching, College English

\begin{abstract}
As an important part of college English teaching, English writing teaching has a direct impact on the quality of English teaching. Discourse analysis constructs the whole structure of the article and is of great benefit to writing. This paper analyzes the main contents of discourse analysis and gives the writing teaching suggestions from the aspects of discourse analysis training, model imitation analysis and outline writing analysis in college English teaching to provide some references for the relative researchers.
\end{abstract}

\section{Introduction}

English writing reflects the students' language ability and plays an important role in English learning. At present, the problems of College Students' writing mainly focus on vocabulary, grammar and text. Among them, the problem at the textual level is especially serious. Language learning has its inherent regularity. In the long-term practice of language learning, people are constantly groping, and constantly find. People's knowledge of language learning goes through the following processes: vocabulary based vocabulary learning, sentence based sentence pattern learning and text based text learning. Language learning should be based on text. This is a conclusion drawn from many practical and scientific experiments. It is a grasp of the nature of language learning. If our teaching is not based on text, then foreign language teaching is bound to take many detours. The text layout ability is weak, the sentence structure lacks transformation, the front and back connection method is monotonous. An article should be semantically coherent and logical, without certain textual cohesive devices. Cohesion in English is quite abundant, some are used at sentence level, others are used at discourse level, and some can be used at different levels. As beginners lack systematic cognitive mental representation training in the process of English language acquisition, it is bound to be influenced by the mother tongue in the process of expressing meaning in English. The expression of some concepts does not follow the coherent expression of English or the habit of thinking in the text, but it is forced to form words according to the Chinese way of expression or thinking, resulting in mistakes in writing. Good command of discourse analysis to English writing is of great help. It can enhance the logical thinking of students, so that English is not the simple pile of sentences, but through coherence, cohesion and form a complete essay, improve the students' writing level.

\section{Main Content of Discourse Analysis}

Category Structure. Different language classes and different ways of using language are different. For example, the use of language should be straightforward, concise, clear and easy to understand, but in poetry and other languages, the use of language is more implicit and highly literary and artistic. In daily teaching, students should also be able to master and familiarize themselves with the language usage of different language classes so that they can write idiomatic English compositions. The teachers often only before the exam taking some lessons focused on grammar, correct spelling, written sentence, happy back and in attention to teaching and training will be mainly on the argumentative practice, as for some other practical style such as letters, invitations, resume, 
cover letter is almost forgotten by the training for teachers and students as a result, the students can only apply the argumentative essay writing in the same corny tone. Unable to apply what they have learned, and apply what they learn directly to their lives and their future work. Therefore, it is imperative for students to understand and master the features of different language structures and their relationship with language use. As we all know, different cultural traditions tend to produce different linguistic structures. As to the structure of letters between the two languages as an example: the structure of letters is generally: Chinese appellation, text and ending ceremony, your signature, date, and the structure of English letters is usually: header, inside address, date, salutation, body, tail, subject your signature. Under the negative influence of the structure of Chinese letters, students often write letters at the end of the letter when they write English letters. Therefore, in the teaching of everyday writing, students are required to understand the genre structure in various practical genres.

Text Structure. Discourse features, namely cohesion and coherence, are important means to help the text express the whole meaning. Cohesion is an important part of textual features, which is embodied in the surface structure of text. Coherence is the semantic connection in text, which is embodied in the deep structure of text and achieves semantic connection through logical reasoning. Text cohesion consists of anaphora, substitution, ellipsis, conjunction and lexical cohesion. These cohesive devices can effectively strengthen the coherence of texts and achieve semantic relatedness from formal features. The analysis of discourse structure aims at the analysis of the organization and internal structure of English articles. It extracts the gist, soul, and structure of the article. There are different forms of discourse in different genres. The cohesion and coherence between sentences are different, and the order of arrangement is different. Through discourse analysis, understand the layout of discourse, discourse coherence and ideological expression. According to systemic functional linguistics, the genre response is different from the cultural context, and is dynamic. A general genre has a beginning, a middle, and an ending. The beginning of the narrative is to explain the time, the place and the characters. The middle part is the description and development of the event, and the ending is the ending of the event or the inspiration. In this article, discourse structure analysis is used to analyze the model, the narrative structure of the story in the article is divided into six parts, namely the abstract, direction, progress, comment, outcome and response. Talking about the structure of the article is a kind of persuasion of the reader's point of view, hope that readers can follow the author's wishes to think about the article and take appropriate action. The beginning of the problem, indicating the existence of the article to discuss the problem, the main part of the problem of analysis, discussion, analysis of arguments.

Paragraph Structure. The cohesive relation and internal logic relation between sentences are not only the elements that constitute paragraph coherence, but also make the whole paragraph center prominent and logical. Because English have their own characteristics, in discourse cohesion and coherence of the use of it in teaching writing to students of discourse coherence and cohesion of knowledge, so that they can follow the habits of the English language, comprehensive use of various cohesive devices is very important. The text of the sentence is basically through the relationship between vocabulary and the relationship of cohesion, it even makes the interpretation of the dependence between the two sentences and form cohesion lexical cohesion between sentences in co-occurrence and reiteration directly affects the quality of writing. Therefore, in the teaching of writing, teachers should teach students to use synonyms, synonyms, upper and lower words or generalizations. English is an analytical rational language. The cohesive devices are explicit and varied. While Chinese is a comprehensive sense of language, in most cases the neglect of grammar, sentence exquisite meaning. The cohesive devices are implicit. But in English, we have to add a causal link to show the logical relationship between them. Therefore, to write idiomatic English, we must first understand the means of coherence and cohesion in English paragraphs. In certain sections, coordination between tenses and forms to cohesive function for sentences, verbs and form in the alternate application process shows the time relation of some action or state that exists in occurs, it can also make readers grasp certain narrative clues. 


\section{Penetration Methods of Discourse Analysis in Witting Teaching of College English}

Training of Discourse Analysis. When the subject of the article and paragraph you have a certain understanding, for some articles, can draw the context semantic map, the main content and the frame of the text, at a glance, more comprehensive understanding and understanding of discourse. To cultivate discourse competence, we should first raise awareness and have textual awareness. During listening, speaking, reading and writing, continue to learn text knowledge and learn how to use it. For any English article, don't think of it as a word, grammar, or sentence pattern. It should be regarded as an example and a carrier for the development of text competence. To develop text competence, reading is the breakthrough point, and the other questions are based on reading comprehension. Reading comprehension ability development will promote the ability to do cloze, proofreading and written questions to improve. Discourse awareness means that reading comprehension can not only stay at the sentence level, but should pay attention to the combination of language form and structure with the meaning of language. In reading, we must pay attention to the training of advanced reading skills, and raise the reading comprehension of the sentence level to the reading comprehension of the text level, so that we can really understand the meaning of the article. The discourse level here on reading comprehension at the macro understanding with logical relation, context, grasp the ideas of the author of the theme of the article, through the summary conclusion, understand the author's views and attitude. The cultivation of textual awareness depends on a certain amount of textual input. This consciousness can only be developed and strengthened only when it is constantly understood in many discourses. However, it is far from enough for students to read only the input of their textbooks. A lot of reading training is necessary to master the ability of discourse analysis.

Training of Model Imitation. In the classroom, give the students examples, and guide students to write, called guiding composition. This method can be applied to the teaching of English writing, with examples of sentences and paragraphs from excellent writers. In accordance with the pattern of experienced writers, students can use this mechanical technique to write, so that the sentence structure and paragraphs become perfect. Imitation is a complex psychological process, and it is also an important means of language learning and language training. The premise of a learner's imitation of a language structure is to understand it correctly and store it in memory, while the ability to store linguistic information in memory often depends on the original structure of linguistic knowledge. According to this, the imitation mechanism can also be applied to English writing teaching. The students began to write English compositions without experience, unable to write. Teachers can help select some text, read or recite, mastering grammar and structure model, and then combined with the accumulation of their knowledge, learn the writing skills, structure of the article, and even the individual sentence imitation, to receive a relaxing composition effect. To eliminate the fear of students' English writing so that students initially tasted the joy of success, to inspire more strong writing enthusiasm. In fact, copy writing is a very useful method of writing for students who have poor writing experience and lack basic writing knowledge. It can help students avoid detours and get started easily. Although the word is not fixed, but English is not without rules. In teaching, teachers can make full use of specific teaching models, by the analysis of the classic works of inspiration, so that students are familiar with the basic vocabulary collocation familiar with general rules and special rules of the familiar idiom familiar with basic sentence to master English as a language, which can be a good guide to writing.

Training of Outline Writing. Time limit outline training and composition review is a very important link to improve students' writing ability. From the writing process, the outline is the necessary preparation for the author's writing. From the outline itself, it is a concrete manifestation of the concept of author. The so-called concept of discourse, the discourse structure is the organization design. Writing should start with a large amount of information, more levels and strict reasoning. From various aspects, it will explain the reason and prove its own point of view. Therefore, the idea of planning is very important, so it must prepare the writing outline for the orderly arrangement of materials, start writing. The complete structure of this article is to distinguish the unified level, a clear focus, carefully layout, the argument and argument organically can arrange, in accordance with the 
requirements on the part of the organization, the use of data that decision, to maximize the role of data. Should have the overall situation idea, embarks from the whole to inspect each section in the article occupies the position and the function. Look at the proportion of each part of the distribution is appropriate, length of space is appropriate, each part can serve the center. The logical relationship between the parts should be considered. When writing people often mistake, is not necessarily linked arguments and, some only repeatedly stated the argument, and the lack of effective arguments are a lot of material, the logical relationship between the various parts of the organic no argument is not clear, this article is not required, there is no convincing. To be persuasive, the article must be combined with theory and practice, and the reasoning process is closely logical. Only by adhering to the combination of practice and evaluation, every practice must be evaluated, students can continue to harvest and improve their writing ability. Writing has always been the most difficult of the five skills. The recent research results show that the current overall level of non-English Majors' writing English composition with low quality, even without serious grammatical errors, it is difficult to achieve the smooth nature, semantic coherence. A lot of students' composition structure is loose, not rigorous logic, semantic coherence, statements are grammar translation, namely Chinese English therefore, study from the discourse level of students' writing, found the textual errors to find the causes of the errors will be of great advantage to improve the students' writing level. Discourse bias is more difficult to correct than linguistic form errors, and has become a bottleneck restricting the level of students' English writing. The study of how to overcome textual errors and achieve textual coherence has been one of the focuses of linguists.

\section{Conclusion}

Discourse analysis is an important reform of the English classroom teaching. Discourse analysis helps students set up the whole idea of the text, deeply understand the author's thoughts and the whole meaning of the article. Students can use good textual cohesion and coherent knowledge to write good articles. The research shows that discourse analysis theory has a great influence on writing ability. Through the study of discourse analysis theory and related training, student's writing ability will have a qualitative leap.

\section{References}

[1] Luo Dan, Huang Ling. An analysis of the Effects of Discourse Analysis on the College English Writing [J]. Overseas English, 2014(23): 43-44+53.

[2] Wen Qinhua. A Study on Writing-through-Reading Teaching Model for Self-taught Students Based on Discourse Analysis [J]. College English Teaching and Research, 2013(2): 11-14.

[3] Song Ying. Analysis of Discourse Errors in English Writings by Non-English Majors [J]. Journal of Lanzhou University of Arts and Science (Social Sciences), 2014, 30(4): 103-107.

[4] Pi Yaxin. A Critical Discourse Analysis of English New Reports [J]. Overseas English, 2016(1): 212-214. 